\title{
Retouchée au Féminin: The Gendered Nature of the French Law Mandating Labeling of Digitally Modified Images
}

\author{
Rachel F. Rodgers ${ }^{1,2, *}$ and Katherine Laveway ${ }^{1}$ (D) \\ 1 APPEAR, Department of Applied Educational Psychology, Northeastern University, Boston, MA 02115, USA; \\ laveway.ka@northeastern.edu \\ 2 Department of Psychiatric Emergency \& Acute Care, Lapeyronie Hospital, CHRU, 34000 Montpellier, France \\ * Correspondence: r.rodgers@northeastern.edu
}

check for

updates

Citation: Rodgers, Rachel F., and Katherine Laveway. 2021. Retouchée au Féminin: The Gendered Nature of the French Law Mandating Labeling of Digitally Modified Images. Laws 10: 62. https://doi.org/10.3390/ laws10030062

Received: 5 March 2021

Accepted: 26 July 2021

Published: 31 July 2021

Publisher's Note: MDPI stays neutral with regard to jurisdictional claims in published maps and institutional affiliations.

Copyright: (c) 2021 by the authors. Licensee MDPI, Basel, Switzerland. This article is an open access article distributed under the terms and conditions of the Creative Commons Attribution (CC BY) license (https:// creativecommons.org/licenses/by/ $4.0 /)$.

\begin{abstract}
The majority of advertisements contain thin-ideal imagery that have been digitally modified. A robust body of research has suggested that exposure to these retouched images has negative effects on body image and increases eating disorder risk. Furthermore, these concerns are known to be highly gendered both in nature and in their extent, with women revealing higher levels of concerns predominantly related to thinness. Although not supported as a useful approach by empirical data, in 2017, France introduced a law requiring advertisers to label images featuring models whose weight and/or shape have been altered. These images must bear the label "photographie retouchée", or "retouched image". However, this legislation has been difficult to enforce, as unlike other French legislation related to labeling advertising, its lack of specificity makes it difficult to identify violations. Paradoxically, given its intentions, where applied, uses of the label disproportionately focus on women's bodies in the media, as compared to men's bodies. These findings highlight the need for legislation that is enforceable and supported by the allocation of sufficient resources. In addition, findings highlight the importance of grounding legislation and policy in the extant relevant data and involving strategic stakeholders in its creation.
\end{abstract}

Keywords: policy; advertisement; digital modification

\section{Introduction}

The saturation of the visual environment with images of unrealistic bodies has been highlighted as a major contributing factor to population levels of body image concerns and eating disorder risk (Levine and Murnen 2009; Want 2009). Although noted to be increasing among men, such concerns continue to disproportionately affect women (Frederick et al. 2007). Consistent with this, gender differences exist in media representation with unrealistic, sexualized, and objectified representations of women outnumbering those of men (Stankiewicz and Rosselli 2008). In recent years, limitations on the use of digital modification in media imagery and advertising have aimed to reduce harmful media influences on men's and women's body image. In 2017, new legislation was passed in France targeting this in print media. The aim of the present study was to explore the ways in which this legislation is both explicitly and implicitly gendered in its conceptualization and implementation, and critically interrogate its capacity to protect individuals across genders from harmful and unrealistic media depictions.

\subsection{Gendered Media Imagery: Unrealistically Thin and Objectifying}

Media images represent unrealistic appearances and bodies, such as portrayals of women depicting extreme thinness (Hesse-Biber et al. 2006; Spitzer et al. 1999). In contrast, images depicting men most often emphasize extreme and visible muscularity (Leit et al. 2001). These depictions are highly discrepant from population-level weights and shapes, and the divergence between average weight and shape among the population and that depicted in the media has been steadily increasing in recent decades (Spitzer et al. 1999). 
Most media images are digitally modified to achieve these unrealistic depictions (Taylor et al. 2018). Although much of the alteration of images is focused on the weight and shape of the models depicted, it is notable that other characteristics are also targeted, as the women portrayed in media images are most often not only extremely thin, but also youthful and fair. Thus, facial features and skin tone, among other aspects, are also the target of digital modification (Hunter 2011; Magdaraog 2014).

Although the majority of media images are extremely unrealistic and rendered more extreme through digital modification, these characteristics tend to be exacerbated in images and media portraying women. First, advertisements portraying female bodies are more frequent than those portraying men (Conley and Ramsey 2011; Thomas and Treiber 2000). In addition, characteristics that render images harmful in terms of their appearance potence tend to be more strongly emphasized in images portraying women. In this way, for example, women are more frequently portrayed in sexualized ways through the positioning of their bodies and faces, the amount of skin visible, the angle of the camera, or in the engagement of a sexually suggestive act (Stankiewicz and Rosselli 2008). Content analyses have revealed that female figures in advertising tend to be sexualized and objectified more than male figures (Monk-Turner et al. 2008). While this may not be directly related to their shape and weight, it is often associated with little clothing and a focus on appearance as opposed to functionality, both of which make the images more "appearance-potent" (Jankowski et al. 2014). Consistent with this, content analyses from the early 1990s revealed that the amount of dieting-related content and advertising was tenfold higher in magazines targeting female readerships as compared to those targeting men (Andersen and DiDomenico 1992).

\subsection{The Detrimental Impact of Media Images on Health}

Thin-ideal imagery has been shown to have a negative impact on the mental and physical health of men and women across the lifespan, particularly in terms of elevated body image concerns, eating disorder risk, and negatively impacting mood. A range of correlational, longitudinal, and experimental studies have supported an association between increased exposure to thin-ideal imagery and these concerns across genders (Levine and Murnen 2009; Blond 2008; Barlett et al. 2008). These effects have been framed within sociocultural theories that highlight how the presence of unattainable bodies in the media is harmful to body image, as individuals come to judge themselves by this unrealistic standard (Thompson et al. 1999). One of the processes held to account for this is appearance comparison, that is, comparisons of one's own appearance against that of the models portrayed in media (Want 2009). Importantly, appearance comparisons are increasingly understood to be automatic processes, and as such are difficult to modulate through conscious effort (Bessenoff 2006). Thus, the unachievable appearances portrayed in most media images lead to appearance comparisons that are unfavorable and may increase body image concerns and eating disorder risk, particularly among those most vulnerable.

\subsection{Policy Approaches Targeting Digital Modification and the French Law}

Given these documented effects, increasing support has emerged for regulatory approaches capable of mitigating the effects of exposure to unrealistic and idealized media images and thus protecting individuals from their harmful effects. The majority of these efforts have involved the use of disclaimer labels on digitally modified images, with the rationale that highlighting these images as modified would decrease their perceived suitability as appearance comparison targets, and therefore prevent negative effects on body image.

In 2012, legislation emerged in Israel requiring disclaimers to be included on images in which models' bodies had been edited to look thinner (Bromberg et al. 2019). Furthermore, it is specified that this notification must appear in a prominent place, be of a color and size that allows them to be read, and cover an area of at least $7 \%$ of the advertisement (Bromberg et al. 2019; Gladstone 2016). At the time, this appeared to be a positive change with the potential to mitigate the effects of thin-ideal imagery, but the effectiveness of 
this law has been called into question due to other protections to individual freedoms of expression (Gladstone 2016).

More recently, in France, the "photographie retouchée" Law was passed in May 2017 and was intended to take full effect in October of the same year ("Décret n ${ }^{\circ}$ 2017-738 du 4 mai 2017 relatif aux photographies à usage commercial de mannequins dont l'apparence corporelle a été modifiée", 2017). The law requires commercial images featuring models whose weight and/or shape have been altered to bear the label "photographie retouchée", or "retouched image." Importantly, the law specifies that violations of the requirement of labeling qualifying digitally modified images may incur heavy fines of up to 37,500 euros, or $30 \%$ of the costs of the advertisement (French Public Health Code 2017).

However, unlike the Israeli law, as well as other French legislation mandating the labeling of certain advertisements, no specifications are mentioned regarding the positioning or formatting of the label other than it be legible. In contrast, for example, the French law regulating the promotion of certain foods (with added salt, sugar, sugar substitutes, or that are highly processed) requires that the labels defined by the "Manger Bouger" campaign be $100 \%$ of the width and $7 \%$ of the height of print type advertisements (Arrête du 27 février 2007 fixant les conditions relatives aux informations à caractère sanitaire devant accompagner les messages publicitaires ou promotionnels en faveur de certains aliments et boissons 2007). This lack of specificity, as well as the vagueness as to what constitutes "weight and shape", and the lack of resources allocated to enforcement all limit the law's usefulness. Despite the description of the fines associated, no documented violations of the law have yet been recorded to date (Danthinne and Rodgers 2020).

Furthermore, the law creates no incentive for increasing body diversity in media, but rather continued leniency towards the use of digital modification to create harmful unrealistic images, which compounds its lack of usefulness. It is notable that these legislative efforts primarily place the emphasis on individuals modifying their response to images, rather than requiring systemic change in the visual environment.

\section{The Gendering of the Text of the French Law}

French is a gendered language, in which most collective nouns, including those describing professional categories, exist only in masculine form, regardless of the gender breakdown of said profession, or stereotypical gender representations. In addition, when referring to a group of individuals of diverse gender, adjectives and verbs take on the masculine plural, while the feminine plural is only used to qualify exclusively female subjects. In this way, the legislative text refers to the bodies of "models" in the masculine form. In addition, when describing digital modifications meeting the requirements for the label, the law describes changes that "slim down or thicken" the figure of the model. In using such language, it seems that the intention is to capture modifications that aim to create unrealistic thinness as well as muscularity. Thus, through both its grammar, and its choice of terminology, the text of the French law is inclusive, and does not specifically target women.

While not explicitly crafted in gendered language, therefore, it is interesting to consider the context and rationale upon which the legislation was built. The 2017 law successfully emerged some years after a previous version was first put forth by the deputy Valérie Boyer in 2009. At the time, deputy Boyer placed the proposal in the context of other contemporary legislation aiming to provide protections against factors encouraging or increasing risk for Anorexia Nervosa (Proposition de loi 2009). Elements of this legislation that were successfully enacted, then had in particular targeted pro-eating disorder online content, which became illegal.

Again, while the language in the law proposal put forth in 2009, including related eating disorders, remained gender neutral, it is notable that the presentation of the law to the senate and the debate surrounding it were highly gendered. ${ }^{1}$ During the argumenta-

1 The full transcription of these sessions are available online from the French governmental resources. 
tion for the 2009 legislation against "encouragement towards excessive thinness," it was highlighted that the ratio of women to men diagnosed with Anorexia Nervosa was 9/1, emphasizing the gendered nature of the disorder (Session ordinaire XIII législature 2008). While this is true, it is noteworthy that gendered appearance ideals are associated with gendered eating disorder presentations, with men reporting more impairment related to muscularity-oriented eating behaviors and excessive exercise (Gorrell and Murray 2019). Furthermore, the minister specifically noted that "the social pressures to achieve the female appearance ideal," exerted by the media contribute to the development of disordered eating, and in some cases, subsequent eating disorders. Furthermore, later in the debate, minister Roselyne Bachelot-Narquin (Minister for Health and Youth) highlighted that the laws would serve to protect two vulnerable groups including those engaged in professions in which pressures towards thinness are strong such as modelling and dancing as well as girls and young women who aspire to conform to appearance ideals. The rest of the debate similarly focuses on the target female audience of the law proposal, with only three mentions of men as potentially also benefiting from the protections the proposed law afforded.

Taken together, these elements clearly show that in the minds of those who developed and debated the 2009 law proposal, the intended target group was indeed girls and young women. The very contextualization of the law related exclusively to thinness, to the exclusion of concerns related to muscularity, skin color, or youthfulness, firmly anchors the proposal in a gendered framework. Similarly, the causal link established in the rationale for the proposed legislation between appearance pressures from media images, the female thinideal, and prevalence rates of Anorexia Nervosa (Galmiche et al. 2019), a highly gendered eating disorder diagnosis, further promote this gendering. Finally, the explicit mention of those engaged in female-dominated professions, as well as girls and young women in the general population as the target group for the protections afforded by the proposed law add a final layer to the gendered lens adopted by those who developed the initial proposal for the 2017 law. Therefore, while not explicitly gendered in its text, it is clear that in the minds of those who developed and supported the legislation that became successful in 2017, the law was designed for women, and applicable to media images of women. These elements suggest that a gender bias may be present in the application of the law.

The objective of this study was therefore to explore the implementation of the French "photographie retouchée" legislation through a gendered lens and critically interrogate its capacity to protect individuals across genders from harmful and unrealistic media depictions. Specifically, the aim was to explore gender bias in the application of the law. The aim was exploratory and separate to investigations of its usefulness in mitigating body image concerns.

\section{Gender and the Implementation of the French Law}

Although equally applicable across genders in theory, as illustrated above, the spirit of the French law was indeed highly gendered, potentially reflected in its implementation. To explore evidence of gendered implementation, the presence of the "photographie retouchée" label on advertisements in the first 2021 editions of four large circulation French magazines was examined.

\subsection{Magazines Examined}

Six magazines were selected and examined based on their circulation and reach, as well as their target audience.

Monsieur, a French monthly publication existing since 1920, describes itself as targeting men aged $30-55$ years, with a circulation of $188 \mathrm{k}$ readers per edition. Its emphasis is described as being on elegance (fashion, accessories, watches, etc.) as luxurious male passion. Its readership is described as urban and cultivated. In addition to being one the longest standing male publications, Monsieur's focus on lifestyle and clothing made it a useful source for high-end advertising including male models (Monsieur 2021). 
GQ, which describes itself as the definitive men's style magazine, was first published in the United States in 1931; its French counterpart launched in 2008. Like its predecessor, GQ France's content is built around fashion, culture, and lifestyle. The median age of its readership is 33 years, and the brand has a reach of just over $2 \mathrm{M}$ readers in print and digital format. GQ France underwent a redesign in 2021, emphasizing its move away from traditional masculine gender norms and toward a fluid understanding of identity (GQ 2021).

Started in 2016, Garçon is a French magazine with 6 yearly editions, explicitly targeting gay men, with a circulation of $30 \mathrm{k}$ readers per edition (Soret n.d.). As the most mainstream magazine for gay men, Garçon was included here due to the documented emphasis on appearance in gay print (Jankowski et al. 2014) and the potential for images of men that would be more appearance potent and therefore more likely to have been digitally modified.

Marie Claire is a monthly women's fashion magazine that was first published in France in 1937 and is among the top French monthly magazines for women, with a reach of 1.6M readers in France. In addition to fashion, the magazine covers issues of beauty, culture, and society, and defines itself as illustrating values of supporting women in their changing roles. As such, it positions itself as reflecting new femininities that at times include the ostensible naming of unrealistic appearance pressures.

Launched in 1980, Biba is a monthly beauty and fashion magazine targeting women in their 30s. It describes itself as a feminine, optimistic, and daring media brand; in addition to fashion and beauty, the magazine also discusses relationships, sex, and culture. During the month of May 2021, the total number of visits to its website surpassed 14,000,000, and its monthly print audience is currently estimated at 548,000 readers (Alliance pour les Chiffres de la Presse et des Médias 2021). Biba was included here due to its wide readership among French young women, and its usefulness as a women's magazine containing appearancepotent content.

The French edition of Vogue was first issued in 1920, twenty-eight years after its American predecessor. With a global reach of 21.2M, Paris Vogue is one of the world's preeminent luxury fashion publications. With an average readership age of 33 years, Paris Vogue describes itself as a leading observer and major player of the creative scene, reflecting social and cultural evolutions, with a recent focus on inclusion, diversity, and eco sustainability (Vogue 2021).

\subsection{Evidence of the Gendered Implementation of the "Photographie Retouchée" Label}

As illustrated in Table 1, across the 6 magazines examined, the proportion of pages dedicated to advertising varied from $14.8 \%$ (Garçon) to $27.2 \%$ (Marie Claire). Of those, only advertisements portraying individuals were eligible to receive the "photographie retouchée" label. The findings showed that while none of the advertisements that exclusively portrayed male models bore the label, the label did appear on some mixed-gender images. Just over $30 \%$ of the advertisements portraying only female models bore the label, while $20 \%$ of those depicting men and women did. Overall, this is a disappointingly low number, revealing that even for advertisements portraying only women, less than half included the label, with no indication that those without the label were free of digital editing, although this is of course possible. 
Table 1. Proportions of magazine images of men and women bearing the "Photographie Retouchée" label.

\begin{tabular}{|c|c|c|c|c|c|c|c|c|}
\hline & \multirow{2}{*}{$\begin{array}{c}\begin{array}{c}\text { Total } \\
\text { Advertisement } \\
\text { Pages }\end{array} \\
\text { Total } \\
\end{array}$} & \multirow{2}{*}{$\begin{array}{c}\begin{array}{c}\text { Total } \\
\text { Advertisements }\end{array} \\
\text { Total } \\
\end{array}$} & \multicolumn{2}{|c|}{ Female Advertisements } & \multicolumn{2}{|c|}{ Male Advertisements } & \multicolumn{2}{|c|}{$\begin{array}{l}\text { Mixed-Gender } \\
\text { Advertisements }\end{array}$} \\
\hline & & & Total & With Labels & Total & With Labels & Total & With Labels \\
\hline & N (\%) & $\mathbf{N}$ & N (\%) & $\mathrm{N}(\%)$ & $\mathrm{N}(\%)$ & $\mathrm{N}(\%)$ & N (\%) & $\mathrm{N}(\%)$ \\
\hline \multicolumn{9}{|l|}{ Men's Magazines } \\
\hline GQ (139 pages) & $24(17 \%)$ & 22 & $0(0 \%)$ & $0(0 \%)$ & $8(33.3 \%)$ & $0(0 \%)$ & $3(12.5 \%)$ & $2(66.6 \%)$ \\
\hline Garçon (142 pages) & $21(14.8 \%)$ & 21 & $0(0 \%)$ & $0(0 \%)$ & $8(38.1 \%)$ & $0(0 \%)$ & $1(4.7 \%)$ & $0(0 \%)$ \\
\hline \multirow{2}{*}{\multicolumn{9}{|c|}{ Women's Magazines }} \\
\hline & & & & & & & & \\
\hline Marie Claire (250 pages) & $68(27.2 \%)$ & 59 & $21(36 \%)$ & $8(38 \%)$ & $2(3 \%)$ & $0(0 \%)$ & $4(5.8 \%)$ & $0(0 \%)$ \\
\hline Biba (124 pages) & $23(19 \%)$ & 21 & $12(57 \%)$ & $4(33 \%)$ & $0(0 \%)$ & $0(0 \%)$ & $0(0 \%)$ & $0(0 \%)$ \\
\hline Vogue (164 pages) & $40(23 \%)$ & 25 & $22(88 \%)$ & $4(19 \%)$ & $0(0 \%)$ & $0(0 \%)$ & $1(4 \%)$ & $0(0 \%)$ \\
\hline Total & $203(26 \%)$ & 171 & $55(32 \%)$ & $16(29 \%)$ & $26(15 \%)$ & $0(0 \%)$ & $10(6 \%)$ & $2(20 \%)$ \\
\hline
\end{tabular}

\section{Discussion}

The French "photographie retouchée" law builds on the tradition of warning and disclaimer labels as public health policy approaches. While these approaches have a broad range of applications, perhaps most saliently in their use related to tobacco and alcohol products, in France, the 2017 law built on legislation mandating labels on specific food products as mentioned above. Indeed, in the initial 2009 proposal, the bill was crafted based on the language used in those laws (Proposition de loi 2009). While there is a strong public health tradition for such approaches, their effectiveness is less clear. Furthermore, the purported mechanism of the warning labels on tobacco products, or those on advertisements for food and beverages, is different to that proposed for the "photographie retouchée" label. In the former case, the label is intended to serve as a deterrent against consumption based on an emphasis on negative health consequences. In the case of the "photographie retouchée" label, the proposed mechanism (although not necessarily clearly articulated by policymakers) is presumably to protect individuals from harmful appearance comparisons, or the belief that the appearances portrayed are attainable, by emphasizing the fact that they are fake. In this latter case, the target is not purchasing or consumption, but rather a cognitive process, a process largely understood to be automatic (Want 2009). Thus, the extent to which warning labels on unrealistic media images may be helpful is unclear.

To examine this question, a number of experimental studies have explored the effects of exposure to thin-ideal images bearing warning labels on immediate changes in body image, mood, and other relevant dimensions among young women. Overall, findings from two recent meta-analyses have shown there to be little evidence for such labels to be protective of body image (Danthinne et al. 2020; McComb and Mills 2020). In contrast, several studies have suggested that the use of warning labels might increase short-term negative effects of thin-ideal images on body image and appearance comparisons (Danthinne et al. 2020; Tiggemann et al. 2013). Thus, the available experimental data reveal no usefulness of approaches such as the "photographie retouchée" label.

In addition, qualitative research among college-aged women has suggested that while the negative impacts of digitally modified and unrealistic appearances are recognized, this does not prevent young women from wishing to attain these appearances (Anh 2019; Borau and Nepomuceno 2019). Broader qualitative research among adult consumers has similarly revealed skepticism regarding the usefulness of such labels, with corresponding greater support for approaches that lead to greater diversity in media images (Paraskeva et al. 2017). Thus, taken together, there is little evidence that the label would serve its protective role among girls and young women. Given this, the lack of systematic implementation of the label documented in the current findings may not be a useful target for increased compliance and enforcement efforts.

Although limited due to being non-systematic and the small sample of print media examined, the findings from our examination of the gender differences in the implementation of the "photographie retouchée" label suggest that it is far more frequently used in 
images depicting women as compared to those depicting men. This is particularly striking in that none of the images that contained only men bore the label, while some of those portraying men and women did. While these findings possibly reflect effective differences in the practices in digital modification of a company depending on the gender of their models, it seems that a more plausible explanation is that the label is more often affixed when the model is female. This gendered implementation of the "photographie retouchée" label thereby contributes to a social context in which women's bodies are singled out as problematic, and policed in various ways (Berry et al. 2020; Piran 2017). This emphasis on women's bodies as problematic perpetuates the discourse that promotes body image concerns and body shame among women, as well as a tendency to internalize this social policing of their bodies (Harper and Tiggemann 2008; Piran 2017). In addition, it allows for the continued portrayal of unrealistic images, rather than encouraging systemic change in the bodies portrayed and promoting diversity.

Although well intentioned, this French "photographie retouchée" law may thus, paradoxically, created unintended negative effects both at the individual level and at the macrolevel. Indeed, data suggest the potential for a "boomerang" effect of images bearing warning labels (Danthinne et al. 2020). Further, evidence exists to suggest that these labels may, in some cases, increase appearance comparisons and be further detrimental to body image. In sum, even if appropriately enforced, the law may not reveal any usefulness.

\section{Conclusions}

The harmful effects of unrealistic media depictions on body image and mental health have been documented (Levine and Murnen 2009). Although these effects are known to occur across gender, the media environment is more densely saturated in unrealistic and appearance-potent images of women as compared to men (Monk-Turner et al. 2008). Consistent with this, social pressures to achieve media ideals are stronger among women who report higher rates of body image concerns and engagement in harmful appearancechanging behaviors (Schaefer et al. 2017). The French "photographie retouchée" law recognizes the role of media images in these concerns and illustrates an attempt to use regulation to mitigate the harmful effects of media images. While not explicitly gendered in its form and texts, the background and rationale for the legislation, as well as its implementation, are highly gendered, as well as inconsistent, contributing to an unhelpful construction of the female body as problematic. In addition, experimental data strongly suggest that the addition of the "photographie retouchée" label is not helpful for individuals exposed to media images bearing it, while the law essentially continues to tolerate or even support the use of digital modification in media imagery.

As an example of an attempted regulatory solution to the problem of unrealistic media images, the French "photographie retouchée" law therefore emerges as unsuccessful. Nevertheless, given the lack of incentives for practices to change and the scope of the problem, exploring alternative policy avenues appears critical. Grounding future legislation in empirically-supported strategies would likely afford a higher potential for success, and strategic research aiming to inform this process is therefore necessary (Brownell and Roberto 2015; Rodgers et al. 2017). Furthermore, evaluation of both the implementation and the effects of such legislation would be useful to continue to inform further efforts. Effective policy approaches that can successfully lead to greater diversity in the bodies and appearances portrayed in the media, or even better limit the amount of appearance-potent media that individuals are exposed to, are essential to decrease universal risk for body image and eating concerns.

Given these documented effects, increasing support has emerged for regulatory approaches capable of limiting the use of digital modification with the goal of diversifying the bodies portrayed and thus protecting individuals from their harmful effects.

Author Contributions: Conceptualization, R.F.R.; methodology, R.F.R.; investigation, R.F.R.; formal analysis, R.F.R.; data collection, R.F.R.; writing-original draft preparation, R.F.R.; writing-review and editing, K.L. All authors have read and agreed to the published version of the manuscript. 
Funding: This research received no external funding.

Institutional Review Board Statement: Not applicable.

Informed Consent Statement: Not applicable.

Data Availability Statement: The data presented in this study are available upon reasonable request from the corresponding author.

Conflicts of Interest: The authors declare no conflict of interest.

\section{References}

\section{Archival Sources}

Décret n 2017-738 du 4 mai 2017 relatif aux photographies à usage commercial de mannequins dont l'apparence corporelle a été modifiée. 2017.

(Proposition de loi 2009) Proposition de loi relative aux photographies d'images corporelles retouches. 2009. Available online: https:/ / www.assemblee-nationale.fr/13/propositions/pion1908.asp (accessed on 5 March 2021).

(Session ordinaire XIII législature 2008) 2008. Assemblée nationale XIII législature Session ordinaire de 2007-2008. Available online: https: / / www.assemblee-nationale.fr/13/cri/2007-2008/20080141.asp (accessed on 5 March 2021).

(French Public Health Code 2017) 2017. Article L2133-2. Code de la Santé Publique: Chapitre III: Alimentation, Publicité et Promotion. (Articles L2133-1 à L2133-2). Available online: https:/ / www.legifrance.gouv.fr/codes/article_lc/LEGIARTI000032411563 (accessed on 5 March 2021).

\section{Published Sources}

Alliance pour les Chiffres de la Presse et des Médias. 2021. Marque Bibamagazine. Available online: https://www.acpm.fr/Marque/ marque-bibamagazine (accessed on 5 March 2021).

Andersen, Arnold E., and Lisa DiDomenico. 1992. Diet vs. shape content of popular male and female magazines: A dose-response relationship to the incidence of eating disorders? International Journal of Eating Disorders 11: 283-87. [CrossRef]

Anh, H. 2019. College-Aged Female Consumers' Meanings of the Digitally-Enhanced Figures in Fashion Advertising and Their Interpretations of the Israel's Photoshop Law. Journal of Ethnographic E Qualitative Research 14: 79-94.

Barlett, Christopher P., Christopher L. Vowels, and David A. Saucier. 2008. Meta-analyses of the effects of media images on men's body-image concerns. Journal of Social and Clinical Psychology 27: 279-310. [CrossRef]

Berry, Rachel A., Rachel F. Rodgers, and Jenna Campagna. 2020. Outperforming iBodies: A Conceptual Framework Integrating Body Performance Self-Tracking Technologies with Body Image and Eating Concerns. Sex Roles 85: 1-12. [CrossRef]

Bessenoff, Gayle R. 2006. Can the media affect us? Social comparison, self-discrepancy, and the thin ideal. Psychology of Women Quarterly 30: 239-51. [CrossRef]

Blond, Anna. 2008. Impacts of exposure to images of ideal bodies on male body dissatisfaction: A review. Body Image 5: 244-50. [CrossRef]

Borau, Sylvie, and Marcelo V. Nepomuceno. 2019. The Self-Deceived Consumer: Women's emotional and attitudinal reactions to the airbrushed thin ideal in the absence versus presence of disclaimers. Journal of Business Ethics 154: 325-40. [CrossRef]

Bromberg, Marilyn, Madeleine Hay, Tomas Fitzgerald, and Catarina de Freitas. 2019. You Are Beautiful, No Matter What They Say: Applying an Evidence-Based Approach to Body Image Law. Issues in Law and Medicine 34: 183.

Brownell, Kelly D., and Christina A. Roberto. 2015. Strategic science with policy impact. The Lancet 385: 2445-46. [CrossRef]

Conley, Terri D., and Laura R. Ramsey. 2011. Killing us softly? Investigating portrayals of women and men in contemporary magazine advertisements. Psychology of Women Quarterly 35: 469-78. [CrossRef]

Danthinne, Elisa S., and Rachel F. Rodgers. 2020. "Photographie Retouchée": Using policy to address body image. Havard Health Policy Review, September 15.

Danthinne, Elisa S., Francesca E. Giorgianni, and Rachel F. Rodgers. 2020. Labels to prevent the detrimental effects of media on body image: A systematic review and meta-analysis. International Journal of Eating Disorders 53: 647-61. [CrossRef] [PubMed]

Frederick, David A., Gordon B. Forbes, Kristina E. Grigorian, and Johanna M. Jarcho. 2007. The UCLA Body Project I: Gender and ethnic differences in self-objectification and body satisfaction among 2206 undergraduates. Sex Roles 57: 317-27. [CrossRef]

Galmiche, Marie, Pierre Déchelotte, Gregorie Lambert, and Marie P. Tavolacci. 2019. Prevalence of eating disorders over the 2000-2018 period: A systematic literature review. The American Journal of Clinical Nutrition 109: 1402-413. [CrossRef] [PubMed]

Gladstone, Julie. 2016. The skinny on BMI-based hiring: An assessment of the legality and effectiveness of Israel's weight restriction law. Washington University Global Studies Law Review 15: 495.

Gorrell, Sasha, and Stuart B. Murray. 2019. Eating Disorders in Males. Child and Adolescent Psychiatric Clinics of North America 28: 641-51. [CrossRef] [PubMed]

GQ. 2021. France GQ Media Kit. Available online: https:/ /www.condenast.com/brands/gq\#France (accessed on 5 March 2021).

Harper, Brit, and Marika Tiggemann. 2008. The effect of thin ideal media images on women's self-objectification, mood, and body image. Sex Roles 58: 649-57. [CrossRef] 
Hesse-Biber, S., Patricia Leavy, Courtney E. Quinn, and Julia Zoino. 2006. The mass marketing of disordered eating and eating disorders: The social psychology of women, thinness and culture. Women's Studies International Forum 29: 208-24. [CrossRef]

Hunter, Nicole. 2011. Beauty is in the eye of the retoucher: Why photoshopped magazine images require regulation. Women's Rights Law Reporter 33: 82.

Jankowski, Glen S., Helen Fawkner, Amy Slater, and Marika Tiggemann. 2014. "Appearance potent”? A content analysis of UK gay and straight men's magazines. Body Image 11: 474-81. [CrossRef]

Leit, Richard A., Harrison G. Pope Jr., and James J. Gray. 2001. Cultural expectations of muscularity in men: The evolution of Playgirl centerfolds. International Journal of Eating Disorders 29: 90-93. [CrossRef]

Levine, Michael P., and Sarah K. Murnen. 2009. "Everybody knows that mass media are/are not [pick one] a cause of eating disorders": A critical review of evidence for a causal link between media, negative body image, and disordered eating in females. Journal of Social and Clinical Psychology 28: 9. [CrossRef]

Magdaraog, Sheila. 2014. The Beholder and the Beholden: The Portrayal of Beauty in the Context of Philippine Mass Media. Available online: https://www.academia.edu/download/35445853/The_Beholder_and_the_Beholden.pdf (accessed on 5 March 2021).

McComb, Sarah E., and Jennifer S. Mills. 2020. A systematic review on the effects of media disclaimers on young women's body image and mood. Body Image 32: 34-52. [CrossRef] [PubMed]

Monk-Turner, E., Kristy Wren, Leanne McGill, Chris Matthiae, Stephan Brown, and Derrick Brooks. 2008. Who is gazing at whom? A look at how sex is used in magazine advertisements. Journal of Gender Studies 17: 201-9. [CrossRef]

Monsieur. 2021. Media Kit. Available online: https://www.monsieur.fr/kit-media/kit-media-monsieur/ (accessed on 5 March 2021).

Paraskeva, Nicole, Helena Lewis-Smith, and Phillippa C. Diedrichs. 2017. Consumer opinion on social policy approaches to promoting positive body image: Airbrushed media images and disclaimer labels. Journal of Health Psychology 22: 164-75. [CrossRef] [PubMed]

Piran, Niva. 2017. Journeys of Embodiment at the Intersection of Body and Culture: The Developmental Theory of Embodiment. Cambridge: Academic Press.

Rodgers, Rachel F., Sara Ziff, Alice S. Lowy, Kimberly Yu, and S. Bryn Austin. 2017. Results of a strategic science study to inform policies targeting extreme thinness standards in the fashion industry. International Journal of Eating Disorders 50: 284-92. [CrossRef]

Schaefer, Lauren M., Jennifer A. Harriger, Leslie J. Heinberg, Taylor Soderberg, and J. Kevin Thompson. 2017. Development and validation of the sociocultural attitudes towards appearance questionnaire-4-revised (SATAQ-4R). International Journal of Eating Disorders 50: 104-17. [CrossRef]

Soret, Christophe. n.d. Home [LinkedIn Page]. LinkedIn. Available online: https:/ fr.linkedin.com/in/christophe-soret-b7067016 (accessed on 4 March 2021).

Spitzer, Brenda L., Katherine A. Henderson, and Marilyn T. Zivian. 1999. Gender differences in population versus media body sizes: A comparison over four decades. Sex Roles 40: 545-65. [CrossRef]

Stankiewicz, Julie M., and Francine Rosselli. 2008. Women as sex objects and victims in print advertisements. Sex Roles: A Journal of Research 58: 579-89. [CrossRef]

Taylor, Charles R., Yoon-Na Cho, Carissa M. Anthony, and Danielle B. Smith. 2018. Photoshopping of models in advertising: A review of the literature and future research agenda. Journal of Global Fashion Marketing 9: 379-98. [CrossRef]

Thomas, Melvin E., and Linda A. Treiber. 2000. Race, gender, and status: A content analysis of print advertisements in four popular magazines. Sociological Spectrum 20: 357-71.

Thompson, J. Kevin, Leslie J. Heinberg, Madeline Altabe, and Stacey Tantleff-Dunn. 1999. Exacting Beauty: Theory, Assessment, and Treatment of Body Image Disturbance. Washington: American Psychological Association.

Tiggemann, Marika, Amy Slater, Belina Bury, Kimberly Hawkins, and Bonny Firth. 2013. Disclaimer labels on fashion magazine advertisements: Effects on social comparison and body dissatisfaction. Body Image 10: 45-53. [CrossRef] [PubMed]

Vogue. 2021. France Media Kit. Available online: https:/ / drive.google.com/file/d/14G3eRPPtm2QSRXg9aubL6o34NiuTB4Xo/view (accessed on 5 March 2021).

Want, Stephen C. 2009. Meta-analytic moderators of experimental exposure to media portrayals of women on female appearance satisfaction: Social comparisons as automatic processes. Body Image 6: 257-69. [CrossRef] [PubMed] 